\title{
О МЕТОДОЛОГИЧЕСКОЙ КУЛЬТУРЕ ОБУЧАЮЩИХСЯ В МАГИСТРАТУРЕ
}

\author{
А. А. Фортунатов \\ (Московский гуманитарный университет)
}

\begin{abstract}
Аннотация: В статье рассмотрено понятие методологическая культура личности. Представлена структура методологической культуры личности. Презентована программа дисциплины «Методология и методы организации научного исследования», направленная на формирование у магистров универсальных и общепрофессиональных компетенций, а также их методологическую подготовку к ведению научно-исследовательской деятельности, формированию их методологической и научной культуры.
\end{abstract}

Ключевые слова: методологическая культура; магистратура; развитие личности; научная культура

\section{ON THE METHODOLOGICAL CULTURE OF STUDENTS IN MASTER'S PROGRAMS}

\author{
A. A. Fortunatov \\ (Moscow University for the Humanities)
}

\begin{abstract}
The article is devoted to the issue of personal methodological culture and its structure. We present the syllabus of a course in «Methodology and methods of organizing scientific research» aimed to help masters'students develop both universal and vocation-specific competencies, as well as prepare themselves for conducting individual research and build personal methodological and research culture.

Keywords: methodological culture; master's degree programs; personality development; research culture
\end{abstract}

Для того, чтобы раскрыть понятия «методологическая культура» остановимся на его содержательных характеристиках. Данное понятие рассматривается в работах многих исследователей. Поэтому уточним для начала тот смысл, который мы будем вкладывать в это понятие. Основополагающим в процессе определения «методологической культуры» выступает ее принадлежность к феномену «культура». Сочетание «мето- 
дологическая культура», как отмечают К. Ю. Брешковская, М. А. Кувырталова и Э. В. Шелиспанская, отражает овладение культурой, как системой ценностей, источником знаний о природе, обществе, способах деятельности предполагает иное отношение к преобразованию педагогической теории и практики. Культура, полагают данные авторы, помогает превратить методологический опыт в достояние будущего специалиста, фактор развития его личности, творческого мышления, формирования научного мировоззрения и ценностной позиции (Брешковская, Кувырталова, Шелиспанская, 2015: 36).

Н. Н. Никитина, О. М. Железнякова и М. А. Петухов определяют мето-дологическую культуру как знания философского, общенаучного, конкретно-научного и технологического уровня; проектирование и организация воспитательно-образовательного процесса; осознание, формулирование и творческое решение педагогических задач; методологическая рефлексия (Никитина, Железнякова, Петухов, 2002).

В. В. Краевский дает следующее определение методологической культуры: это «...знание, опыт творческой деятельности, опыт эмоциональноценностного отношения» (Краевский, 2001: 25).

Рассматривая методологическую культуру в качестве одного из струк-турно образующих факторов развития студента как исследователя, Г. Х. Валеев характеризует ее как культуру профессионального мышления, основанную на методологических знаниях, важнейшую часть которых составляет рефлексия. Таким образом, можно утверждать, что методологическая культура студента - это культура мышления, основанная на методологических знаниях, умениях, навыках, способности к рефлексии, научному обоснованию, критическому осмыслению и творческому применению определенных концепций, форм и методов познания, управления и конструирования (Валеев, 2001). Соответственно, термин «методологическая культура» можно рассматривать как совокупность достижений человечества в области научной методологии.

Интерес для нас представляет исследования В. А. Сластенина, который полагает, что основными признаками методологической культуры являются:

- понимание процедур, «закреплённых» за категориями философии и за основными понятиями, образующими концептуальный каркас педагогической науки;

- осознание различных понятий образования как ступеней восхождения от абстрактного к конкретному;

- установка на преобразование педагогической теории в метод познавательной деятельности;

- направленность мышления на генезис педагогических форм и их 
«целостнообразующие» свойства;

- потребность воспроизводить практику образования в понятийно терминологической системе педагогики;

- стремление выявить единство и преемственность педагогического знания в его историческом развитии;

- доказательное опровержение антинаучных позиций в области человекознания;

- понимание мировоззренческих, гуманистических функций педагогики и психологии и др. (Сластенин, Исаев, Шиянов, 2007).

Поскольку культура личности - это «качество личности как субъекта деятельности», характеризующее высокую степень его достижений в какой-либо области, то, как полагает М. С. Красин, «методологическая культура личности» - это качество личности, характеризующее высокую степень усвоения методологических знаний, вплоть до овладения умением использовать нормы научной методологии для решения проблемных ситуаций в различных областях и формирования убеждённости в необходимости руководствоваться основными положениями научной методологии при организации учебной, научной и практической (в том числе, социальной) деятельности (Красин, 2011: 74-75).

Е. Г. Вегнер рассматривает методологическую культуру как «высший уровень методологической компетентности» (Вегнер, 2007: 5). С этим сложно не согласиться, т. к. методологическая культура предполагает наличие опыта успешного применения усвоенных методологических знаний не в одной предметной области (когда уже можно говорить о наличии компетентности), а в нескольких. Н. В. Шаронова отмечает, что важнейшим компонентом методологической культуры выступают мировоззренческие и аксиологические убеждения: «На основе убеждений формируются идеалы, принципы, непосредственно выполняющие регулятивную роль в поведении личности» (Шаронова, 1997: 37).

Наличие внутренних убеждений в ценности методологических норм оберегает субъекта деятельности от принятия решений, кажущихся, на первый взгляд, простыми, но не согласующимися с принципами и правилами научной методологии, и поэтому, в конечном счёте, приводящими к существенным просчётам. Именно личное принятие методологических знаний, пишет М. С. Красин, в качестве естественных, а не навязанных извне, регулятивов деятельности выступает одним из основных показателей наличия методологической культуры (Красин, 2011: 75).

Методологическая культура личности не может быть сформирована без постоянного наполнения методологических норм примерами из той или иной конкретной предметной области. Получение опыта применения методологических знаний происходит в процессе выполнения того 
или иного вида деятельности. Таким видом деятельности, как мы полагаем, является научно-исследовательская деятельность. В качестве примера рассмотрим формирования методологической культуры магистранта в процессе освоения дисциплины «Методология и методы организации научного исследования».

К обязательным дисциплинам базовой части учебного плана магистров по направлению подготовки 44.04.02 - «Психолого-педагогическое образование» относится дисциплина «Методология и методы организации научного исследования». Процесс изучения данной дисциплины направлен на формирование следующих компетенций:

1. Общепрофессиональных компетенций:

-(ОПК-6) владение современными технологиями проектирования и организации научного исследования в своей профессиональной деятельности на основе комплексного подхода к решению проблем профессиональной деятельности;

2. Профессиональных компетенций:

- (ПК-36) готовность использовать современные научные методы для решения научных исследовательских проблем;

•(ПК-37) способность разработать и представить обоснованный перспективный план научной исследовательской деятельности;

(ПК-40) способность представлять научному сообществу научные исследовательские достижения в виде научных статей, докладов, мультимедийных презентаций в соответствии с принятыми стандартами и форматами профессионального сообщества.

В соответствии с требованиями стандарта программа дисциплины «Методология и методы организации научного исследования» направлена на формирование прописанных компетенций и имеет целью формирование у обучающихся-магистрантов способности к научноисследовательской деятельности в области общей педагогики, истории педагогики и образования, основ методологической культуры.

Цель изучения дисциплины конкретизируется в задачах:

- сформировать систему научных знаний о методологии и системном подходе при организации и построении научно-исследовательской деятель-ности, связанной с исследованием педагогических проблем;

- раскрыть понятийный аппарат, методы исследовательской деятельности в области общей педагогики, истории педагогики и образования, требования к их выбору и модификации;

- развивать научное, аналитическое мышление будущих магистров, развитие исследовательских, конструктивных, прогностических компетенций;

- формировать личностную психолого-педагогическую направлен- 
ность педагога-исследователя, ценностные гуманистические ориентации, интерес к самостоятельному исследованию актуальных проблем воспитания, обучения и образования; практическую готовность к написанию и защите магистерской диссертации.

В результате изучения дисциплины «Методология и методы организации научного исследования» обучающийся должен:

1. Знать:

- методологические основы современного научного исследования;

- особенности психолого-педагогического исследования в области общей педагогики, истории педагогики и образования;

- требования к современному научному исследованию на уровне магистерской диссертации;

2. Уметь:

- логично и грамотно формулировать и высказывать свои мысли, выдвигать и доказывать гипотезу;

- применять теоретические и эмпирические методы исследования;

- оценивать научную новизну, теоретическую и практическую значимость исследования на уровне магистерской диссертации;

- создавать мультимедийные презентации в соответствии с принятыми стандартами и форматами профессионального сообщества;

2. Владеть:

- методологией научно-исследовательской деятельности в области общей педагогики, истории педагогики и образования;

- способами организации исследовательской деятельности;

- способами представлять научному сообществу научные исследовательские достижения в виде научных статей, докладов.

В программу дисциплины включено рассмотрение на лекциях и практических занятиях следующих вопросов:

1. Гуманитарные исследования в современном социуме: проблема организации научного исследования в образовательных учреждениях;

2. Методология и принципы научного исследования в области педагогики, истории педагогики и образования;

3. Методы научного исследования в области педагогики, истории педагогики и образования;

4. Педагогический эксперимент как метод научного исследования;

5. Магистерская диссертация в системе обучения студентов в магистратуре гуманитарного университета.

Подводя итоги вышесказанному следует отметить, что реализация в полном объеме представленной программы дисциплины «Методология и методы организации научного исследования» позволяет подготовить обучающихся к успешному осуществлению научной и научно- 
исследовательской деятельности через овладение методологической культурой. Овладение данным видом культуры предполагает, в том числе, и знание критериев качества и результативности научных исследований. Во всех программных документах, определяющих модели развития науки, образования и инновационного предпринимательства в Российской Федерации до 2020 г., отмечена необходимость достижения мирового уровня исследований, а, следовательно и развитие высокого уровня методологической культуры.

\section{СПИСОК ЛИТЕРАТУРЫ}

Брешковская, К. Ю., Кувырталова, М. А., Шелиспанская, Э. В. (2015) Методологическая культура как условие развития конкурентоспособности будущих психологов // Обеспечение качества учебного процесса: традиции и инновации: материалы XLII учебно-методической конференции профессорско-преподавательского состава, аспирантов, магистрантов, соискателей ТГПУ им. Л. Н. Толстого. Тула : Изд-во ТГПУ им. Л. Н. Толстого. С. 34-39.

Валеев, Г. Х. (2001) Формирование методологической культуры педагога-исследователя. Челябинск ; Стерлитамак. 192 с.

Вегнер, Е. Г. (2007) Формирование методологической компетентности будущего учителя географии средствами модульного обучения : автореф. дис. ... канд. пед. наук. М. 51 с.

Краевский, В. В. (2001) Методология педагогики : пособие для педагогов-исследователей. Чебоксары : Изд-во Чуваш, ун-та. 244 с.

Красин, М. С. (2011) О методологической культуре личности и стратегии ее развития у обучающихся в школе // Вестник Калужского университета. № 2. С. 74-80.

Никитина, Н. Н., Железнякова, О. М., Петухов, М. А. (2002) Основы профессионально-педагогической деятельности. М. : Мастерство. 288 с.

Сластенин, В. А., Исаев, И. Ф., Шиянов, Е. Н. (2007) Педагогика : учеб. пособие для студ. высш. пед. учеб. заведений / под ред. В. А. Сластенина. М. : Издательский центр «Академия». 576 с.

Шаронова, Н. В. (1997) Теоретические основы и реализация методологического компонента методической подготовки учителя физики: автореф. дис. ... д-ра пед. наук. М. 34 с.

Дата поступления: 10.12.2016 г.

Фортунатов Артем Александрович - кандидат педагогических наук, доцент кафедры педагогики и психологии высшей школы Московского гуманитарного университета. Адрес: 111395, Россия, г. Москва, ул. Юности, д. 5 Тел.: +7 (499) 374-74-59. Эл. адрес: art_fortunatov@mail.ru 
Fortunatov Artem Aleksandrovich, Candidate of Pedagogy, Associate Professor, Department of Pedagogy and Psychology of Higher School, Moscow University for the Humanities. Postal address: 5 Yunosti St., 111395 Moscow, Russian Federation. Tel.:+7 (499) 374-74-59. E-mail: art_fortunatov@mail.ru

\section{Для цитирования:}

Фортунатов А. А. О методологической культуре обучающихся в магистратуре [Электронный ресурс] // Научные труды Московского гуманитарного университета. 2016, № 6. URL: http://journals.mosgu.ru/trudy/article/view/374 (дата обращения: дд.мм. гг.). 